\title{
Implementasi Algoritma Massey-Omura dan Algoritma Elias Delcta Code Pada Pengamanan dan Kompresi File Dokumen
}

\author{
Rosalina Manalu \\ Program Studi Teknik Informatika, STMIK Budi Darma, Medan, Indonesia \\ Email: rossamanalu3005@gmail.com
}

\begin{abstract}
Abstrak-Semakin pesatnya perkembangan teknologi informasi mengharuskan para pengguna untuk lebih berhati-hati dalam menjaga kerahasiaan dan keamanan data agar data tidak diketahui atau dimanipulasi oleh pihak lain. Pengamanan data merupakan hal yang sangat penting bagi para penguna, keamanan data suatu data dapat dijaga oleh setiap orang. Kriptografi salah satu alat keamanan yang digunakan untuk menyandikan suatu file dokumen. Salah satunya dengan menggunakan Algoritma Massey-Omura yang merupakan algoritma kriptografi asimetris, sehingga memiliki kunci yang berbeda untuk melakukan enkripsi dan dekripsi. Dalam proses pengriman data, juga dibutuhkan durasi pengiriman file untuk tidak memberi kesempatan kepada pencuri data yaitu dengan memampatkan data atau mereduksi ukuran file supaya lebih kecil tanpa menghilangkan isi dari file dokumen, sehingga waktu proses pertukaran data dapat lebih singkat. Kompresi data merupakan proses dimana file text, audio, maupun video ditransformasikan menjadi file terkompresi dengan ukuran data yang lebih kecil namun tidak kehilangan informasi yang sebenarnya. Penelitian ini membahas jenis kompresi lossless, sehingga file yang didapatkan dari hasil dekompresi akan identik dengan data asli. Elias Delta Code merupakan jenis kompresi lossless. Parameter kinerja dari algoritma ini akan diukur dengan Ratio of Compression (RC, Space Saving (SS) dan waktu kompresi. Data yang digunakan pada proses pengujian yaitu data yang terdiri dari beberapa jenis karakter. Pada pembahasan ini akan meliputi penjelasan, cara kerja, kelebihan dan kekurangannya. Penulis juga akan mencoba memberikan ulasan cara untuk meningkatkan tingkat keamanan file dokumen.
\end{abstract}

Kata Kunci: Kriptografi, Pengamanan, Kompresi, File, Massey-Omura, Elias Delcta Code.

Abstract-The rapid development of information technology requires users to be more careful in maintaining data confidentiality and security so that data is not known or manipulated by other parties. Data security is very important for users, data security can be maintained by everyone. Cryptography is one of the security tools used to encode a document file. One of them is by using the Massey-Omura algorithm, which is an asymmetric cryptographic algorithm, so that it has different keys for encryption and decryption. In the process of sending data, it also requires the duration of sending files to not give an opportunity to data thieves by compressing the data or reducing the size of the file to be smaller without losing the contents of the document file, so the data exchange process can be shorter Data compression is a process where text, audio, and video files are transformed into compressed files with smaller data sizes but do not lose the actual information. This study discusses the type of lossless compression, so that files obtained from decompression will be identical to the original data. Elias Delta Code is a type of lossless compression. The performance parameters of this algorithm will be measured by Ratio of Compression (RC, Space Saving (SS) and compression time. Data used in the testing process is data that consists of several types of characters. In this discussion will include explanation, how to work, advantages and The author will also try to provide a review of ways to improve the security level of document files.

Keywords: Cryptography, Security, Compression, Files, Massey-Omura, Elias Delcta Code.

\section{PENDAHULUAN}

Pengamanan data dan informasi merupakan kebutuhan penting yang harus diperhatikan dalam bidang komunikasi. Terlebih kemajuan teknologi informasi dewasa ini, memberikan dampak positif dan negatif bagi masyarakat seperti kemudahan memperoleh informasi, penyebaran informasi, pengiriman data dan pertukaran data. Media komunikasi umum yang digunakan saat ini sangat rawan terhadap penyadapan informasi oleh pihak-pihak yang tidak berkepentingan terhadap informasi tersebut.

Kriptografi adalah salah satu ilmu yang mempelajari teknik-teknik matematika yang berhubungan dengan aspek pengamanan informasi seperti kerahasiaan data, integritas data dan ontentikasi data. Dengan kriptografi data akan diubah menjadi sandi yang hanya dapat diartikan oleh pihak yang memiliki kunci yang akan digunakan untuk mengubah sandi menjadi data asli.

Algoritma Massey-Omura merupakan algoritma kriptografi kunci publik berbasis eksponensial yang diusulkan oleh James Massey dan Jim K. Omura pada 1982. Algoritma ini didasarkan pada ide Adi Shamir yaitu Shamir's three-pass protocol atau Shamir's no-keys protocol. Pada algoritma Massey-Omura ukuran file setelah enkripsi akan bertambah besar dan didasarkan pada konsep three-pass protocol. Pertukaran pesan akan dilakukan sebanyak tiga kali melalui three-pass protocol ini. Konsumsi transfer atau Bandwidth jaringan juga menjadi salah satu faktor yang mempengaruhi waktu proses pengiriman pesan karena ukuran Bandwidth setara dengan kecepatan waktu pengiriman. Hal ini dapat menyebabkan proses pengiriman menjadi lambat.

Reza et al. melakukan penelitian pengamanan file teks dengan melakukan simulasi pengamanan file dengan menggunakan algoritma Massey-Omura. Dari hasil penelitian diperoleh suatu sistem yang menggunakan algoritma Massey-Omura untuk pengamanan file di mana sistem ini dapat digunakan untuk mengenkripsi dan mendekripsi file teks [1]. Pengujian dengan menganalisis keamanan pada kombinasi protocol Secret Sharing dan Three-Pass. Dari hasil pengujian didapatkan bahwa kombinasi protokol Secret Sharing dan Three-Pass berhasil mengamankan pesan dan mengirimkan pesan tersebut kepada setiap penerimanya [2]. 
Kompresi data atau pemampatan data adalah sebuah cara untuk memadatkan data sehingga hanya memerlukan ruang penyimpanan lebih kecil dan lebih efisien dalam penyimpanan atau mempersingkat pertukaran data. Untuk mengoptimalkan proses pengiriman file diterapkan dengan melakukan kompresi file atau pemampatan data. Untuk itu digunakan sebuah algoritma kompresi data untuk mengecilkan ukuran file enkripsi tanpa ada data yang hilang atau identik dengan data asli.

Untuk proses kompresi ini digunakan algoritma kompresi Elias Delta Code yang merupakan jenis kompresi lossless. Kompresi lossless adalah metode kompresi data yang memungkinkan data asli dapat disusun kembali dari hasil kompresi maka rasio kompresi pun tidak terlalu besar untuk memastikan semua data dapat dikembalikan ke bentuk semula. Kompresi lossless utamanya digunakan untuk data artikel, text, dll. Parameter kinerja algoritma akan diukur dengan Ratio of Compression (RC, Space Saving (SS) dan waktu kompresi.

\section{METODE PENELITIAN}

\subsection{Pengamanan}

Pengamanan adalah proses atau cara mengamankan sesuatu yang bertujuan untuk mencegah ancaman atau gangguan. Dalam ilmu kriptografi, pengamanan sama halnya dengan penyandian teks. Teks rahasia akan disandikan dengan karakter yang berbeda, sehingga karakter tersebut tidak memiliki arti[3].

\subsection{Kompresi}

Teknik kompresi berarti proses memampatkan sesuatu yang berukuran besar sehingga menjadi kecil. Maka kompresi adalah proses untuk memampatkan atau mereduksi data agar ukurannya menjadi kecil. Pemampatan ukuran data/berkas melalui proses kompresinya diperlukann saat data tersebut disimpan dan dikirim melalui media transmisi atau telekomunikasi. Apabila data/berkas tersebut akan ditampilkan lagi pada layar monitor, maka data yang terkompresi tersebut harus dibongkar lagi dan dikembalikan pada format semula agar dapat dibaca kembali. Proses pembongkaran data yang dimampatkan ini disebut dikompresi. Satuan yang mencakup penting dalam kompresi data adalah Compression ratio yang menggambarkan seberapa besar ukuran data setelah proses kompresi dan dibandingkan dengan ukuran data/berkas semula[4].

\subsection{Massey-Omura}

Massey-Omura Cryptosystem adalah cipher berbasis eksponensial yang oleh James Messey dan Jim K. Omura pada 1982. Yang didasarkan pada Shamir's three-pass protocol. Keuntungan dari kriptosistem ini adalah tidak diperlukan distribusi dan pertukaran kunci diantara kedua pihak yang berkomunikasi.

Sebelum melakukan komunikasi dengan menggunakan Massey-Omura Cryptosystem, para koresponden harus memiliki kunci enkripsi dan dekripsi terlebih dahulu dengan syarat[1]:

1. Semua pengguna menyetujui kelompok batasan terhadap bidang tetap batasan $F p$ dengan p sebagai kekuatan utama.

2. Masing-masing pengguna sistem secara rahasia memilih sebuah bilangan bulat acak $e_{A}$ atau $e_{B}$ antara 1 dan $\mathrm{p}$ -1 sebagai calon kunci enkripsi dengan syarat $\operatorname{gcd}\left(e_{A}, \mathrm{p}-1\right)=1 \operatorname{dan} \operatorname{gcd}\left(e_{A}, \mathrm{p}-1\right)=1$

3. Dengan menggunkan algortima euclidean, hitung invers $e_{A}$ dan $e_{A B}$. Invers $e_{A}$ yaitu $e_{A} \equiv e_{A}^{-1}(\bmod p-1)$ sebagai kunci dekripsi pengirim $\left(d_{A}\right)$ dan invers $e_{B}$ yaitu $e_{B} \equiv e_{B}^{-1}(\bmod p-1()$ sebagai kunci dekripsi penerima $\left(d_{B}\right)$.

\subsection{Elias Delta Code}

Elias delta code merupakan kode universal yang mengkodekan bilangan bulat pusat yang dikembangkan oleh Peter Elias. Elias Delta Code merupakan satu dari tiga Elias Code yang dipelopori oleh Peter Elias. Di dalam kode ini, setiap karakter direpresentasikan dengan pemetaan kode sumber ke sejumlah variabel bit. Aturan untuk mengkodekan sebuah bilangan dengan menggunakan Elias Delta Code adalah sebagai berikut :

1. Encoding

Berikut langkah-langkah Encoding pada algortima Elias Delta Code :

a. Tulis bilangan dalam bentuk biner

b. Hilangkan bit paling kiri dari bentuk bilangan biner

c. Hitung sisa bit pada langkah ke-2 dan tambahkan 1 kemudian tuliskan hasilnya dalam bentk biner di depan bilangan pada langkah ke-2.

d. Kemudian hitung jumlah bit pada langkah ke-3 dan kurangi 1 kemudian tulisakan jumlahnya dalam bentuk biner 0 lalu sisipkan pada awalan bilangan langkah ke-3.

2. Decoding

Langkah-langkah mendecoding algoritma Elias Delta Code sebagai berikut :

a. Baca bilangan biner 0 sampai ditemukan angka 1 ,

b. Jumlah bilangan biner 0 dengan 1 atau $n^{\prime}+1$ 
c. Baca bit bilangan setelah biner 0 sesuai hasil yang didapatkan pada langkah ke-2. Lalu kurrangkan dengan 1 sehingga didapatkan $n$.

d. Dapatkan binagn encodenya dengan menjumlahkan $2^{\wedge} n+x, x$ merupakan bilangan sisa[2].

Tabel 1. Elias Delta Code

\begin{tabular}{ccccc}
\hline Number & $\mathrm{N}$ & $\mathrm{N}+1$ & Encoding & Probability \\
\hline $1=2^{0}+0$ & 0 & 1 & 1 & $1 / 2$ \\
$2=2^{1}+0$ & 1 & 2 & 0100 & $1 / 16$ \\
$3=2^{1}+0$ & 1 & 2 & 0101 & $1 / 16$ \\
$4=2^{2}+0$ & 2 & 3 & 01100 & $1 / 32$ \\
$5=2^{2}+1$ & 2 & 3 & 01101 & $1 / 32$ \\
$6=2^{2}+2$ & 2 & 3 & 01110 & $1 / 32$ \\
$7=2^{2}+3$ & 2 & 3 & 01111 & $1 / 32$ \\
$8=2^{3}+0$ & 2 & 4 & 00100000 & $1 / 256$ \\
$9=2^{3}+1$ & 3 & 4 & 00100001 & $1 / 256$ \\
$10=2^{3}+2$ & 3 & 4 & 00100010 & $1 / 256$ \\
$11=2^{3}+3$ & 3 & 4 & 00100011 & $1 / 256$ \\
$12=2^{3}+4$ & 3 & 4 & 00100100 & $1 / 256$ \\
$13=2^{3}+5$ & 3 & 4 & 00100101 & $1 / 256$ \\
$14=2^{3}+6$ & 3 & 4 & 00100110 & $1 / 256$ \\
$15=2^{3}+7$ & 3 & 4 & 00100111 & $1 / 256$ \\
$16=2^{4}+0$ & 4 & 5 & 001010000 & $1 / 512$ \\
$17=2^{4}+1$ & 4 & 5 & 00101001 & $1 / 512$ \\
\hline
\end{tabular}

\section{HASIL DAN PEMBAHASAN}

Analisa sistem (system analysis) merupakan proses awal pembangunan sistem dengan melakukan identifikasi terhadap komponen-komponen yang dibutuhkan oleh sistem. Analisa dapat dilakukan dengan menentukan komponen yang menjadi input, proses sistem, dari output dari sistem. Analisa masalahmerupakan proses identifikasi sebab akibat dibangunnya sebuah sistem agar sistem dapat berjalan sesuai dengan tujuan sistem. Pada penelitian ini perlunya pengamanan file yang berkaitan dengan aspek pengamanan file untuk menghindari bahaya seperti manipulasi isi file oleh pihak yang tidak bersangkutan. algoritma Elias Delta Code. File yang akan diamankan adalah berekstensi .doc. Sistem akan melakukan empat jenis proses yaitu proses enkripsi, kompresi dekompresi dan dekripsi. Pertukaran pesan akan dilakukan sebanyak tiga kali sesuai dengan konsep Three-PassProtocol.

\subsection{Analisa Pengamanan Algoritma Massey-Omura}

Berikut ini adalah cara kerja algoritma Massey-Omura dalam pengamanan file dokumen. Sebagai contoh, A hendak mengirim dokumen kepada B dengan nama file "LAPORAN ROSALINA". Keduanya menyetujui bilangan prima lebih besar dari 256, misalnya $\mathrm{p}=257$.

1. Pengirim memilih eA, dimana $1<\mathrm{eA}<\mathrm{p}-1$ dan eA koprima $\mathrm{p}-1$.

a. Misalkan eA $=151$, karena 59 adalah koprima dengan 257. Nilai eA digunakan dalam proses enkripsi.

b. Pengirim menghitung invers eA berdasarkan persamaan pertama (1), dan kemudian disimpan dengan $\mathrm{dA}=39$, jika dihitung $(151 \times 39) \bmod 256=1$ memenuhi syarat. Nilai dA digunakan dalam proses enkripsi.

2. Penerima menghitung eB, dimana $1<\mathrm{eB}<\mathrm{p}-1$ dan eB koprima dengan $\mathrm{p}-1$

a. Misalkan eB $=25$, karena 25 adalah koprima dengan 257. Nilai eB digunakan dalam proses enkripsi.

b. Penerima menghitung invers eB berdasarkan persamaan ketiga (3), maka penyimpanan dalam $\mathrm{dB}=41$, jika dihitung $(25 \times 41)$ mod 256=1 memenuhi syarat. Nilai dB digunakan dalam proses dekripsi.

\section{Proses enkripsi pesan}

Nama dokumen yang hendak dikirim adalah "LAPORAN ROSALINA"

1. Shinta mengkonversi karakter pesan dengan bilai ASCII sebagai berikut:

\begin{tabular}{llllllll}
\hline $\mathrm{L}=74$ & $\mathrm{~A}=65$ & $\mathrm{P}=80$ & $\mathrm{O}=79$ & $\mathrm{R}=82$ & $\mathrm{~A}=65$ & $\mathrm{~N}=78$ & Spasi=32 \\
\hline $\mathrm{R}=82$ & $\mathrm{O}=79$ & $\mathrm{~S}=83$ & $\mathrm{~A}=65$ & $\mathrm{~L}=76$ & $\mathrm{I}=73$ & $\mathrm{~N}=79$ & $\mathrm{~A}=65$ \\
\hline
\end{tabular}

2. Enkripsi setiap karakter pesan berdasarkan persamaan kedua (2).

$\mathrm{C} 2=\mathrm{C}^{\mathrm{eA}} \bmod \mathrm{p}$

$\mathrm{eA}=151$

$\mathrm{p}=257$

Untuk L : $76^{151} \bmod 257=220$ 
Untuk A : $65^{151} \bmod 257=80$

Untuk P : $80^{151} \bmod 257=251$

Untuk O : $79^{151} \bmod 257=104$

Untuk R : $82^{151} \bmod 257=14$

Untuk A : $65^{151} \bmod 257=80$

Untuk N : $78^{151} \bmod 257=94$

Untuk SPACE $=32^{151} \bmod =8$

Untuk R : $82^{151} \bmod 257=14$

Untuk O : $79^{151} \bmod 257=104$

Untuk S : $83^{151} \bmod 257=204$

Untuk A : $65^{151} \bmod 257=80$

Untuk L : $76^{151} \bmod 257=220$

Untuk I : $73^{151} \bmod 257=22$

Untuk N : $78^{151} \bmod 257=94$

Untuk A : $65^{151} \bmod 257=80$

Jadi hasil C1 =

\begin{tabular}{llllllll}
\hline 220 & 80 & 251 & 104 & 14 & 80 & 94 & 8 \\
\hline 14 & 104 & 204 & 80 & 220 & 22 & 94 & 80 \\
\hline
\end{tabular}

3. Jika dikonversi ke karakter maka hasilnya adalah :

\begin{tabular}{cccccccc}
\hline$\ddot{U}$ & $\mathrm{P}$ & $\hat{\mathrm{U}}$ & $\mathrm{H}$ & & $\mathrm{P}$ & $\wedge$ & \\
\hline & $\mathrm{H}$ & $\grave{\mathrm{I}}$ & $\mathrm{P}$ & $\ddot{\mathrm{U}}$ & & $\wedge$ & $\mathrm{P}$
\end{tabular}

4. Pengirim mengrim $\mathrm{C} 1$ kepada penerima

5. Penerima mengenkripsi $\mathrm{C}$ berdasarkan persamaan

$\mathrm{C} 2=C 1^{e B} \bmod \mathrm{p}$

$\mathrm{eB}=25$

$\mathrm{p}=257$

Untuk Ü : $220^{25} \bmod 257=149$

Untuk P : $80 \quad 25 \bmod 257=107$

Untuk û : $251^{25} \bmod 257=154$

Untuk h : $104^{25} \bmod 257=13$

Untuk : $14^{25} \bmod 257=238$

Untuk P : $80^{25} \bmod 257=107$

Untuk $^{\wedge}=94^{25} \bmod 257=125$

Untuk : $8^{25} \bmod 257=249$

Untuk : $14^{25} \bmod 257=238$

Untuk h : $104^{25} \bmod 257=13$

Untuk Ì : $204^{25} \bmod 257=6$

Untuk P : $80^{25} \bmod 257=107$

Untuk Ü : $220^{25} \bmod 257=149$

Untuk : $22^{25} \bmod 257=169$

Untuk $^{\wedge}: 94^{25} \bmod 257=125$

Untuk P : $80^{25} \bmod 257=107$

Jadi hasil C2 :

\begin{tabular}{llllllll}
\hline 149 & 107 & 154 & 13 & 238 & 107 & 125 & 249 \\
\hline 238 & 13 & 6 & 107 & 149 & 169 & 125 & 107 \\
\hline
\end{tabular}

6. Penerima mengiri $\mathrm{C} 2 \mathrm{ke}$ pengirim

7. Pengirim mengenkrip $\mathrm{C} 2$ berdasarkan persaman (5) dan menghasilkan $\mathrm{C} 3$

$\mathrm{C} 3=C 2^{d A} \bmod \mathrm{p}$

$\mathrm{eB}=39$

$\mathrm{p}=25$

Untuk $149^{39} \bmod 257=145$

Untuk $107^{39} \bmod 257=212$

Untuk $154^{39} \bmod 257=107$

Untuk $13^{39} \bmod 257=139$

Untuk $238^{39} \bmod 257=183$

Untuk $107^{39} \bmod 257=212$

Untuk $125^{39} \bmod 257=186$

Untuk $249^{39} \bmod 257=225$

Untuk $238^{39} \bmod 257=183$ 
Untuk $13^{39} \bmod 257=139$

Untuk $6^{39} \bmod 257=177$

Untuk $107^{39} \bmod 257=212$

Untuk $149^{39} \bmod 257=145$

Untuk $169^{39} \bmod 257=46$

Untuk $125^{39} \bmod 257=186$

Untuk $107^{39} \bmod 257=212$

Jadi hasil C3 adalah :

\begin{tabular}{llllllll}
\hline 145 & 212 & 107 & 139 & 183 & 212 & 186 & 225 \\
\hline 183 & 139 & 177 & 212 & 145 & 46 & 186 & 212 \\
\hline
\end{tabular}

Dikonversi kepada karakter, maka hasilnya adalah :

\begin{tabular}{|c|c|c|c|c|c|c|c|}
\hline 6 & $\hat{\mathbf{O}}$ & $\mathbf{K}$ & 1 & ' & $\hat{\mathbf{O}}$ & o & $\mathbf{P}$ \\
\hline • & $<$ & \pm & $\hat{\mathbf{O}}$ & 6 & - & 0 & $\hat{\mathbf{O}}$ \\
\hline
\end{tabular}

Diman C3 adalah cipher dari pesa asli dari pengirim ke penerima.

\section{Proses Dekripsi file}

1. Cipher yang telah diterima oleh penerima adalah :

\begin{tabular}{|c|c|c|c|c|c|c|c|}
\hline 45 & 212 & 107 & 139 & 183 & 212 & 186 & 225 \\
\hline 183 & 139 & 177 & 212 & 145 & 46 & 186 & 212 \\
\hline 6 & $\hat{\mathrm{O}}$ & $\mathrm{K}$ & 1 & ' & $\hat{\mathrm{O}}$ & o & $\mathrm{P}$ \\
\hline . & $<$ & \pm & $\hat{\mathrm{O}}$ & ' & . & o & $\hat{\mathrm{O}}$ \\
\hline
\end{tabular}

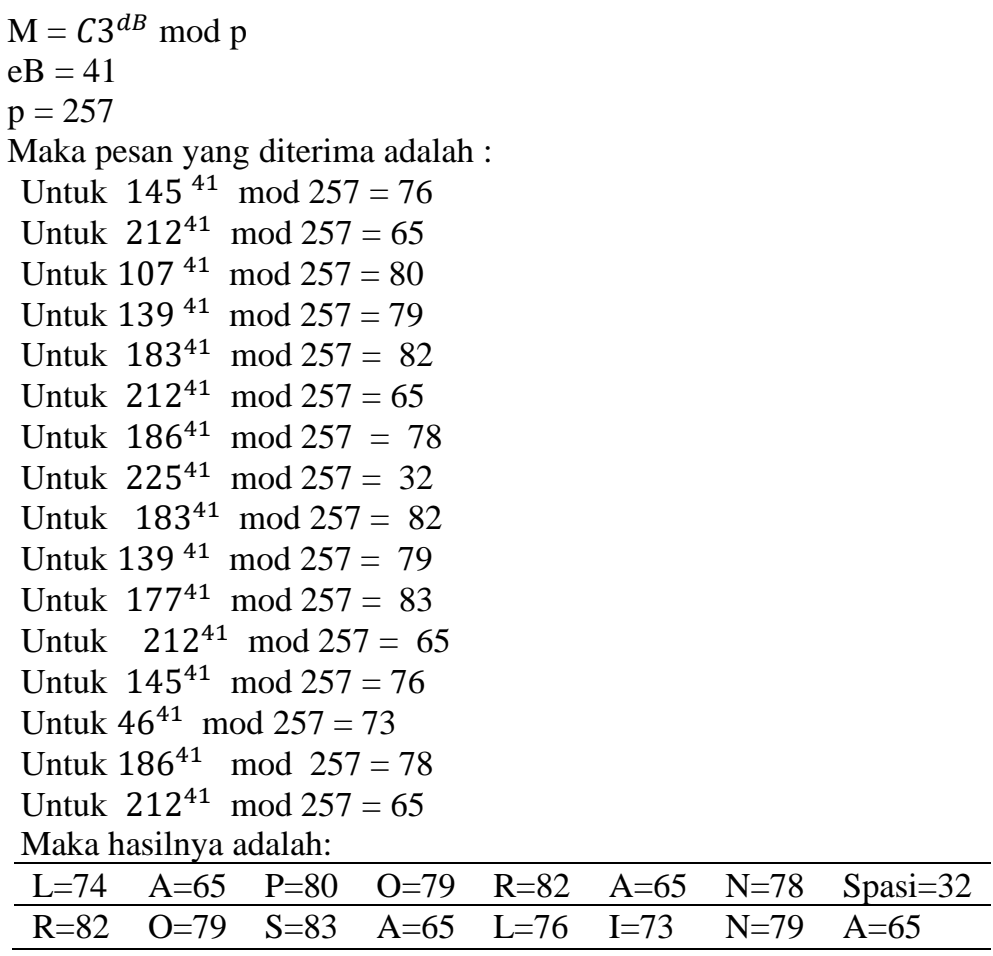

Hasil dekripsi diatas dikonversi ke dalam karakter sebgai pesan asli yang diterima oleh penerima yaitu : LAPORAN ROSALINA.

\subsection{Analisa Kompresi Algoritma Elias Delta Code}

Berikut ini analisa perhitungan untuk mengkompresi File Dokumen dengan Elias Delta Code.

1. Langkah Encoding

a. Contoh pada bilangan $20 \rightarrow 10100$

b. Hilangkan bilangan bit paling kiri $\rightarrow 0100$

c. Sisa bit pada langkah ke- $2+1 \rightarrow 4+1=5$, dalam bentuk biner ditulis 101 , maka bilangan sementara 101| 0100

d. Jumlah bit pada bilangan 101 adalah 3, maka $3-1=2$, sehingga bilangan biner dari langkah ini adalah 00 . Dimasukkan pada bilangan langkah ke-3, sehingga hasilnya adalah 00|101|0100 atau 001010100.

2. Langkah Decoding 
Contoh pada langkah encoding dari algoritma ini dapat diterapkan pada bilangan yang telah di decode sebelumnya yaitu : 001010100 .

1. Baca bilangan 001010100 , maka pada bilangan 0 yaitu 2 buah.

2. Jumlahkan $\mathrm{N}^{\prime}+1=2+1=3$.

3. Selanjutnya adalah membuka 3 bit selanjutnya dari bilangan 0 yaitu $101=5$ lalu dikurangkan dengan 1 maka $\mathrm{N}=5-1=4$

4. Maka bilangan encodenya adalah $(2 \wedge 4)+0=16$

Tabel 2. Tabel Elias Delta Code

\begin{tabular}{ccccc}
\hline Number & $\mathrm{N}$ & $\mathrm{N}+1$ & Encoding & Probability \\
\hline $1=2^{0}+0$ & 0 & 1 & 1 & $1 / 2$ \\
$2=2^{1}+0$ & 1 & 2 & 0100 & $1 / 16$ \\
$3=2^{1}+0$ & 1 & 2 & 0101 & $1 / 16$ \\
$4=2^{2}+0$ & 2 & 3 & 01100 & $1 / 32$ \\
$5=2^{2}+1$ & 2 & 3 & 01101 & $1 / 32$ \\
$6=2^{2}+2$ & 2 & 3 & 01110 & $1 / 32$ \\
$7=2^{2}+3$ & 2 & 3 & 01111 & $1 / 32$ \\
$8=2^{3}+0$ & 2 & 4 & 00100000 & $1 / 256$ \\
$9=2^{3}+1$ & 3 & 4 & 00100001 & $1 / 256$ \\
$10=2^{3}+2$ & 3 & 4 & 00100010 & $1 / 256$ \\
$11=2^{3}+3$ & 3 & 4 & 00100011 & $1 / 256$ \\
$12=2^{3}+4$ & 3 & 4 & 00100100 & $1 / 256$ \\
$13=2^{3}+5$ & 3 & 4 & 00100101 & $1 / 256$ \\
$14=2^{3}+6$ & 3 & 4 & 00100110 & $1 / 256$ \\
$15=2^{3}+7$ & 3 & 4 & 00100111 & $1 / 256$ \\
$16=2^{4}+0$ & 4 & 5 & 001010000 & $1 / 512$ \\
$17=2^{4}+1$ & 4 & 5 & 00101001 & $1 / 512$ \\
$18=2^{4}+2$ & 4 & 5 & 001010010 & $1 / 512$ \\
\hline
\end{tabular}

Selanjutnya pengujian kompresi dilakukan dengan input string LAPORAN ROSALINA meliputi tahapan sebagai berikut :

1. Hitung panjang teks

2. Buat dan hitung panjang himpunan karakter

3. Hitung panjang bit

4. Menentukan Padding bit.

Di bawah ini adalah tabel menunjukkan string asli sebelum proses kompresi. String memiliki 16 karakter.

Tabel 2. String Asli

\begin{tabular}{cccc}
\hline No. & Char & ASCII & Binary \\
\hline 1 & L & 76 & 1001100 \\
2 & A & 65 & 1000001 \\
3 & P & 80 & 1010000 \\
4 & O & 79 & 1001111 \\
5 & R & 82 & 1010010 \\
6 & A & 65 & 1000001 \\
7 & N & 78 & 1001110 \\
8 & Spasi & 32 & 100000 \\
9 & R & 82 & 1010010 \\
10 & O & 79 & 1001111 \\
11 & S & 83 & 1010011 \\
12 & A & 65 & 1000001 \\
13 & L & 76 & 1001100 \\
14 & I & 73 & 1001001 \\
15 & N & 78 & 1001110 \\
16 & A & 65 & 1000001 \\
\hline
\end{tabular}

Kemudian pada tahap selanjutnya karakter berulang akan dihilangkan sehingga hanya tinggal satu karakter. Setelah proses ini, hanya tersisa 9 karakter dengan frekuensi yang berbeda.

Tabel 3. Frekuensi Karakter Elias Delta Code

\begin{tabular}{lllll}
\hline No. Char & ASCII & Binary & Frekuensi & Jumlah Bit \\
\hline
\end{tabular}




\begin{tabular}{cccccc}
\hline 1 & $\mathrm{~L}$ & 76 & 1001100 & 2 & 16 \\
2 & $\mathrm{~A}$ & 65 & 1000001 & 4 & 32 \\
3 & $\mathrm{P}$ & 80 & 1010000 & 1 & 8 \\
4 & $\mathrm{O}$ & 79 & 1001111 & 2 & 16 \\
5 & $\mathrm{R}$ & 82 & 1010010 & 2 & 16 \\
6 & $\mathrm{~N}$ & 78 & 1001110 & 2 & 16 \\
7 & & 32 & 100000 & 1 & 8 \\
8 & $\mathrm{~S}$ & 83 & 1010011 & 1 & 8 \\
9 & $\mathrm{I}$ & 73 & 1001001 & 1 & 8 \\
& & & & 16 & 128 \\
\hline
\end{tabular}

Langkah selanjutnya adalah mengurutkan nilai frekuensi dan mengkonversi nilai Elias Delta Code :

Tabel 4. Pengurutan dan Konversi Elias Delta Code

\begin{tabular}{cccccc}
\hline No. & Char & Frekuensi & $\begin{array}{l}\text { Elias Delta } \\
\text { Code }\end{array}$ & Jumlah Bit & Total Bit \\
\hline 1 & A & 4 & 1 & 1 & 4 \\
2 & L & 2 & 0100 & 4 & 8 \\
3 & O & 2 & 0101 & 4 & 8 \\
4 & $\mathrm{R}$ & 2 & 01100 & 5 & 10 \\
5 & $\mathrm{~N}$ & 2 & 01101 & 5 & 10 \\
6 & $\mathrm{P}$ & 1 & 01110 & 5 & 5 \\
7 & $\mathrm{~S}$ & 1 & 01111 & 5 & 5 \\
8 & $\mathrm{I}$ & 1 & 00100000 & 8 & 8 \\
9 & $\mathrm{Sp}$ & 1 & 00100010 & 8 & 8 \\
& & & & & 66 \\
\hline
\end{tabular}

Adapun parameter algoritma kompresi

1. Ratio Of Compression (Rc)

$$
\begin{aligned}
& \mathrm{Rc}=\frac{\text { bit sebelum kompres }}{\text { bit setelah } \text { kompresi }} \\
& \mathrm{Rc}=\frac{128}{66} \\
& \mathrm{Rc}=1.93
\end{aligned}
$$

2. Compression Ratio

$$
\begin{aligned}
& \mathrm{C}=\frac{\text { bit setelah kompresi }}{\text { bit sebelum kompresi }} \times 100 \% \\
& \mathrm{Cr}=\frac{66}{128} \times 100 \% \\
& \mathrm{Cr}=51.5625 \%
\end{aligned}
$$

3. Redundancy

$$
\begin{aligned}
& R d=\frac{\text { bit sebelum kompresi }- \text { bit setelah kompresi }}{\text { bit sebelum kompresi }} \times 100 \% \\
& =\frac{128-66}{128} \times 100 \% \\
& =\frac{62}{128} \times 100 \% \\
& =\mathbf{4 8 . 4 3 7 5} \%
\end{aligned}
$$

Proses kompresi telah menyimpan data adalah $\mathbf{4 8 . 4 3 7 5 \%}$ dari data asli. tingkat penyimpanan tergantung pada urutan dan pola karakter dari pesan asli.

\section{KESIMPULAN}

Berdasarkan studi literatur, analisa dan implementasi sistem algoritma Massey-Omura dan Elias Delta Code dalam pengamanan dan kompresi file dokumen dapat disimplkan berikut ini :

1. Pengamanan dan kompresi file dokumen dengan konsep Three-pass protocol memenuhi syarat keutuhan file dokumen. Dalam pengamanan pertukaran file dengan menggunakan algoritma Massey-Omura sistem ini melakukan enkripsi dengan menggunakan bilangan prima dan koprima dengan kunci enkripsi yang bersifat rahasia.

2. Kompresi file menggunakan algoritma Elias Delta Code tergantung pada parameter. Semakin besar nilai dari Parameter Compression Ratio, Ratio Compression, Redundancy, dan Space Saving maka semakin kompresi.. 


\section{REFERENCES}

[1] Reza, M., Budiman, M. A. \& Arisandi, D. Simulasi Pengamanan File Teks Menggunakan Algoritma Massey-Omura.Jurnal Dunia Teknologi Informasi 1(1): 20-27, 2012

[2] M Katz, J. \& Lindell, Y. Introduction to modern cryptography (2nd ed., Chapman \& Hall/CRC Cryptography and Network Security Series). Chapman and Hall/CRC. 2014

[3] B Julita, Perbandingan dan Anlisis Algoritma Elias Delta Code dan Algortima Unary Coding Dalam Mengkompresi File Text.Skripsi.USU.2017

[4] Rachmat Antonius, Algoritma dan Pemograman dengan bahasa, Andy:2010

[5] Alfredo S. Implementasi Algoritma Massey-Omura Dalam Pengamanan Teks. Skripsi. STMIK Budidarma: 2015

[6] Https://en.wikipedia.org/File.2018

[7] Sedianingsih. Teori dan Praktik Administrasi Kesekretariatan. Andy.Yogyakarta:2015.

[8] Dony Ariyus, Pengantar Ilmu Kriptografi Teori Analisis dan Impementasi, Yogyakarta, Andy Offset:2008

[9] Rifki Sadikin, Kriptografi untuk Keamanan Jaringan dan Implementasinya Dalam Bahasa Java, Yogyakarta: Andy: 2012

[10] Haramaini, T. Algoritma One Time Pad pada Three-Pass Protocol. Tesis. Universitas Sumatra Utara.2014Khavita, Kompresi Data Lossless, Skripsi.USU:2016

[11] A.S. Rosa dan Sahaludin. Model Pembelajaran Rekayasa Perangkat Lunak Terstruktur Dan Beriorientasi Object. Bandung: Modula: 2011

[12] P.D.Dr.Suarga.M.Sc.M.Math, ALgoritma dan Pemograman, Yogyakarta: Andy Offset:2012 